\title{
Can dynamic contour tonometry and ocular pulse amplitude help to detect severe cardiovascular pathologies?
}

This article was published in the following Dove Press journal:

Clinical Ophthalmology

14 July 2014

Number of times this article has been viewed

\author{
T Bertelmann' \\ S Langanke' \\ M Potstawa ${ }^{2}$ \\ I Strempel' \\ 'Department of Ophthalmology, \\ Philipps-University of Marburg, \\ Marburg, ${ }^{2}$ Section Cardiology, Internal \\ Medicine Clinic, Schwalmstadt, \\ Germany
}

\begin{abstract}
We demonstrate the close relationship between a conspicuous ocular pulse amplitude and severe underlying cardiovascular disease. Two otherwise symptom-free glaucoma patients without any previously diagnosed underlying cardiovascular pathology but with a conspicuous ocular pulse amplitude and who underwent routine examinations in our glaucoma department were referred to the appropriate specialty for further diagnostic procedures. In both patients, the diagnosis of a tachyarrhythmia was made as suspected on dynamic contour tonometry measurements. In addition to medical treatment, one patient underwent electric cardioversion and the second patient was scheduled for pacemaker implantation. A third patient with an unexpected high ocular pulse amplitude despite severe cardiovascular pathology underwent major surgery due to an aortic aneurysm. Carotid stenosis was diagnosed due to side differences in ocular pulse amplitude as well. Ocular pulse amplitude might be a noninvasive and affordable screening tool and could be used to detect severe cardiovascular disease. A prospective study including a larger number of patients is needed to prove this hypothesis.
\end{abstract}

Keywords: cardiovascular pathology, carotid occlusive disease, dynamic contour tonometry, glaucoma, ocular pulse amplitude, tachyarrhythmia

\section{Background}

Glaucoma continues to be one of the major causes of severe visual impairment and vision loss throughout the world. ${ }^{1}$ In addition to elevated intraocular pressure, reduced ocular perfusion contributes to glaucomatous optic neuropathy. ${ }^{2}$ Dynamic contour tonometry (DCT) is a new method for measuring intraocular pressure (IOP) as well as choroidal perfusion as analyzed by the ocular pulse amplitude (OPA). ${ }^{3}$ Using DCT enables us to immediately report choroidal perfusion as an acoustic or printable signal. ${ }^{4}$ A conspicuous OPA is related to ocular as well as a variety of systemic cardiovascular diseases. $^{5}$

The purpose of this paper is to report further cases in which a conspicuous OPA was the diagnostic tool used to detect severe cardiovascular morbidity and to provide a current review of the literature about the relationship between OPA and systemic cardiovascular disorders, emphasizing the potential diagnostic advantage of DCT measurements in regard to underlying cardiovascular disease in glaucoma patients.

\section{Case reports Case I}

A 60-year-old woman with diagnosed normal tension glaucoma was seen on a regular basis in our department. As measured by DCT, the target IOP was achieved with 
topical glaucoma treatment (IOP $13 \mathrm{mmHg}$ OU [both eyes]). The OPA was rhythmic and in the lower normal range (1.6 mmHg OD [right eye]; $2.1 \mathrm{mmHg}$ OS [left eye]), and corresponding to her distinctive vascular dysfunction. Apart from this condition, there were no attendant symptoms or previously diagnosed cardiovascular diseases. During a periodic check-up, we noted a new arrhythmic OPA, prompting referral of this symptom-free patient to a cardiologist. Electrocardiographic examination revealed a sustained cardiac tachyarrhythmia (TAA), and echocardiographic findings included moderate mitral and tricuspid regurgitation as well as a borderline elevated left ventricular size (Figure 1). An anticoagulant (warfarin) to prevent thromboembolic events and a beta-blocker plus amiodarone to stabilize heart rate and rhythm were administered. After reporting morning cardiac syncope, the patient underwent further medical examinations and was diagnosed with sick sinus syndrome. This necessitated implantation of a cardiac pacemaker, which was performed successfully.

\section{Case 2}

A 69-year-old patient without any known medical conditions but with advanced pseudoexfoliation glaucoma was also seen on a regular basis in our department. During a periodic checkup, IOP ranged between $19 \mathrm{mmHg}$ OD and $17 \mathrm{mmHg}$ OS, and OPA was evaluated to be within normal limits in both eyes (2.0 mmHg OD; $2.8 \mathrm{mmHg}$ OS). However, a new arrhythmic acoustic signal was apparent, so that the patient was referred to a cardiologist. Electrocardiography revealed a TAA (Figure 2) and echocardiography showed severely restricted left ventricular pump function due to TAA, confirming the diagnosis of tachymyopathy (Figure 3). Electrical cardioversion was done and anticoagulant

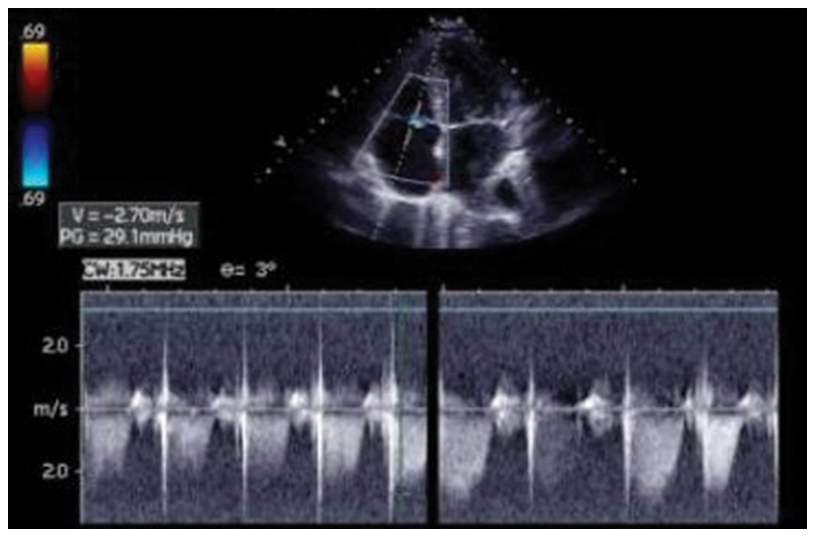

Figure I Echocardiographic finding of a tachyarrhythmic heartbeat and restricted left ventricular pump function.

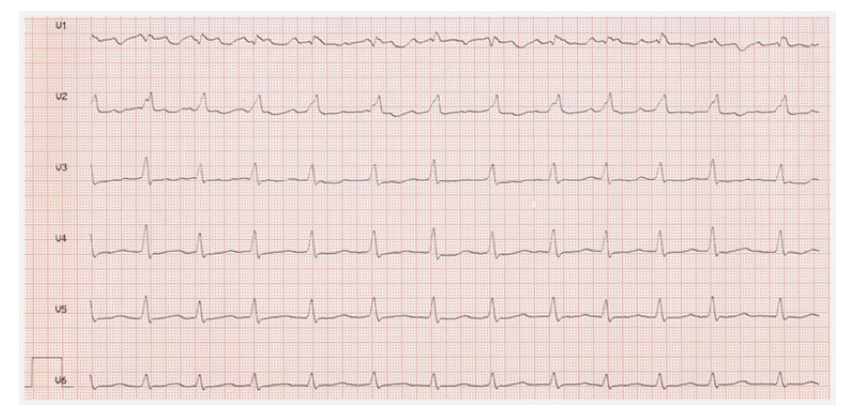

Figure 2 Electrocardiographic finding of a tachyarrhythmic heart due to atrial fibrillation (heart rate $157 \mathrm{bpm}$ ).

therapy with dabigatran was initiated. After 3 months, echocardiographic findings showed an improvement in left ventricular function.

\section{Case 3}

A 77-year-old man suffering from early pigment dispersion glaucoma (IOP $18 \mathrm{mmHg}$ OU) was seen for the first time in our clinic. A low OPA was expected due to his pronounced cardiovascular medical history, including severe coronary heart disease with prior implantation of five coronary artery bypass grafts. DCT and OPA examinations revealed an unequal raised OPA (5.7 $\mathrm{mmHg}$ OD; $7.5 \mathrm{mmHg}$ OS), which prompted a referral to the internal medicine department. A computed tomography angiogram revealed a type $2 \mathrm{~A}$ abdominal aortic aneurysm (Allenberg classification) with a size of $50 \mathrm{~mm} \times 43 \mathrm{~mm}$ (Figure 4). Duplex sonography revealed an intraluminal plaque in the right internal carotid artery, accounting for a $50 \%-60 \%$ stenosis (Figure 5). The patient underwent coiling embolization of the inferior mesenteric artery followed by a successful Y-stent (Figure 6).

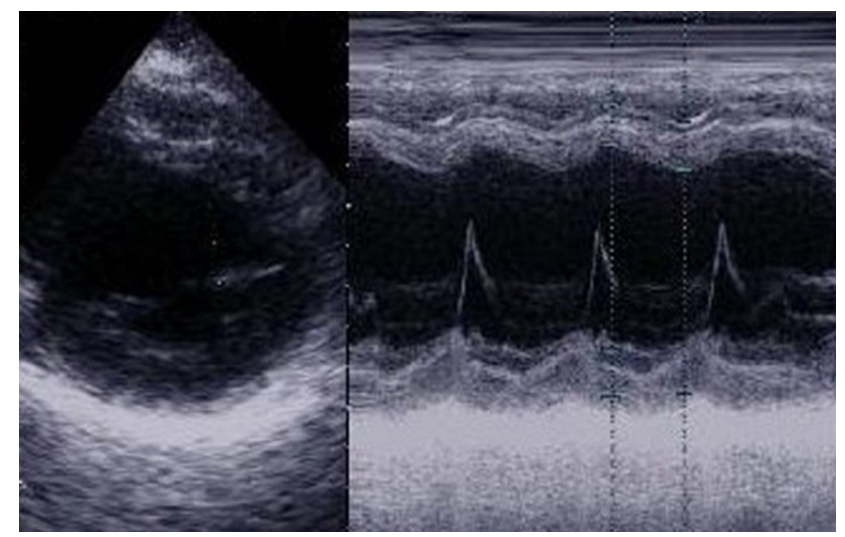

Figure 3 Echocardiographic findings of atrial fibrillation and restricted left ventricular pump function (ejection fraction $32 \%$ ). 


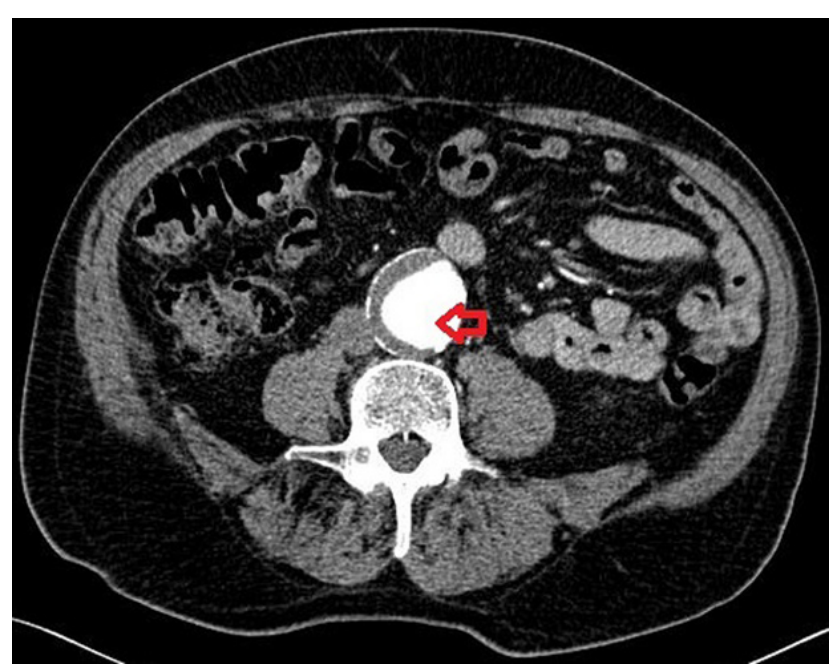

Figure 4 Computed tomography angiogram showing a type $2 \mathrm{~A}$ infrarenal aortic aneurysm (Allenberg classification), size $50 \mathrm{~mm} \times 43 \mathrm{~mm}$ with partial thrombosis (arrow).

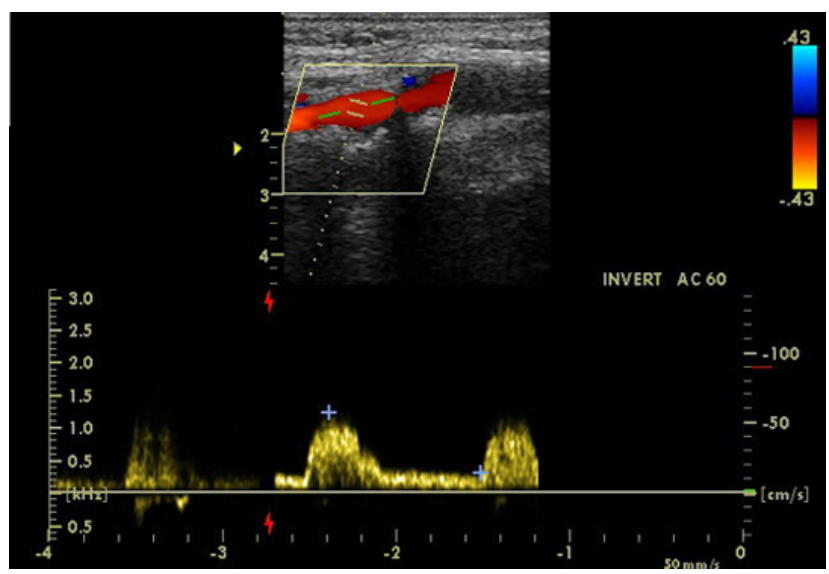

Figure 5 Duplex sonography showing an intraluminal plaque in the right internal carotid artery accounting for a $50 \%-60 \%$ stenosis.

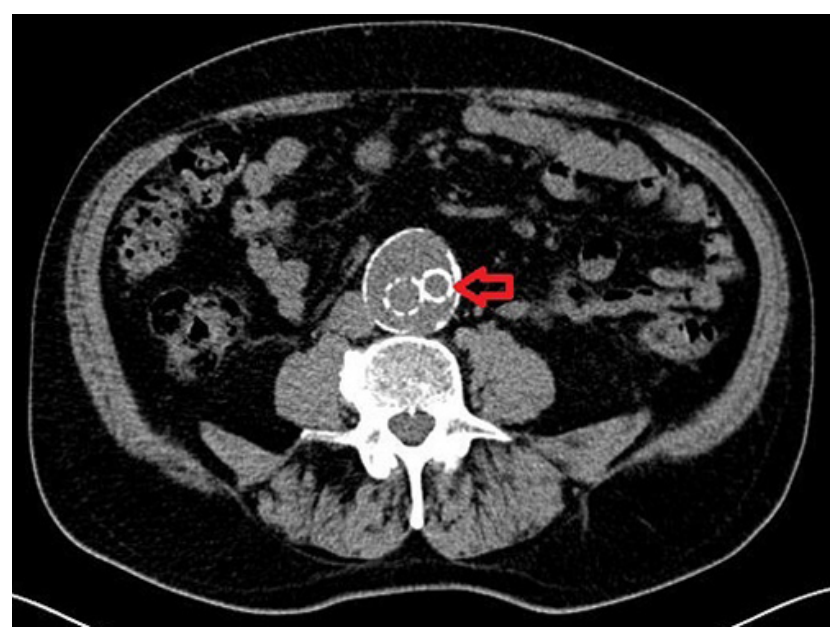

Figure 6 Computed tomography scan after successful implantation of a Y-stent graft (arrow).

\section{Review of the literature}

Measuring IOP by DCT enables us to determine systolic and diastolic IOP simultaneously. The difference between each measurement is defined as the OPA, which is an indirect indicator of choroidal perfusion, thus reflecting the condition of the arterial vascular system and the action of the heart. ${ }^{3}$ The cardiac cycle causes a volume displacement in the choroidal vascular bed, which contributes to $90 \%-95 \%$ of total ocular blood flow ${ }^{6}$ as well as rhythmic pressure changes within the eye. ${ }^{7}$ A major advantage of DCT-assisted measurements is use of a piezoresistive pressure sensor device generating an electric signal during IOP recordings. The latter is converted into an acoustic signal that can be used to analyze the quality of OPA measurements; on the other hand, IOP and OPA levels as well as heart rhythm can be acoustically analyzed by the examiner immediately, ${ }^{3}$ which in turn offers the opportunity for the examining ophthalmologist to detect (severe) cardiovascular abnormalities.

The definition of a "normal" versus a "conspicuous/ pathologic" OPA is still under debate. Reviewing the literature, OPA typically ranges from 2 to $3 \mathrm{mmHg}^{8-10}$ and is usually below $5 \mathrm{mmHg}$. Under healthy conditions, the side difference between the two eyes is less than $0.5 \mathrm{mmHg}$. ${ }^{8,11}$

Cardiovascular morbidity can be detected using OPA by analyzing three aspects of the OPA, ie, the OPA level, comparison of the OPA in the right and left eye, and OPA rhythm. A multitude of various systemic conditions can influence OPA as reviewed in Table 1.

Little information on OPA rhythm is available in the literature. To the best of our knowledge, the impact of TAA on OPA has not been described as yet. As we demonstrated in two of our cases, OPA is an excellent tool for diagnosis of TAA, as an irregular heartbeat can be perceived acoustically during measurement. ${ }^{12}$ OPA depends on the rhythmic time course of cardiac contraction and thus on specific aspects of choroidal filling time, both of which are reduced in TAA. In addition to ocular perfusion issues, TAA has been found to play a major role in severe cardiovascular events like strokes. ${ }^{13}$ Therefore, use of OPA to detect TAA, regardless of whether TAA is continuous, intermittent, or paroxysmal, is accompanied by the need for immediate cardiovascular clarification by a cardiologist to prevent the aforementioned events as well as to determine the individual cardiovascular risk profile of each patient. ${ }^{14,15}$ This aspect should not be overlooked, given that TAA is the most common cardiac TAA affecting $1 \%$ of the population, and can often be asymptomatic. ${ }^{15}$ Palpating the patient's pulse or performing an electrocardiogram is an easier and cheaper way to 
Table I Systemic cardiovascular conditions and their influence on OPA levels/rhythm

\begin{tabular}{|c|c|c|}
\hline CV disorders increasing OPA & CV disorders decreasing OPA & OPA side differences \\
\hline Systolic blood pressure ${ }^{25}$ & Arteriosclerosis ${ }^{9}$ & Carotid obstructive disease ${ }^{|9-2|}$ \\
\hline Heart rate $<90 \mathrm{bpm}^{6}$ & Heart rate $>90 \mathrm{bpm}^{6}$ & Innominate steal syndrome ${ }^{22}$ \\
\hline Left ventricular ejection time ${ }^{12}$ & Vasospasm, vascular dysregulation ${ }^{5,26}$ & Cavernous sinus dural fistula ${ }^{23,24}$ \\
\hline \multirow[t]{3}{*}{ Aortic regurgitation ${ }^{27}$} & Absolute tachyarrhythmia ${ }^{12,15}$ & \\
\hline & Diastolic blood pressure ${ }^{25}$ & \\
\hline & Increasing age $\mathrm{e}^{5}$ & \\
\hline
\end{tabular}

Abbreviations: CV, cardiovascular; OPA, ocular pulse amplitude.

diagnose TAA, but this might not be the routine setting for an ophthalmologist. But even an ophthalmologist can diagnose TAA in otherwise asymptomatic glaucoma patients, which in turn was impossible when measuring IOP using Goldmann applanation tonometry. This provides the advantage of DCT-assisted IOP evaluations. In case 3, we demonstrate an extremely high OPA in a patient with a type $2 \mathrm{~A}$ aortic abdominal aneurysm who needed partial replacement of his aorta with a Y-stent. If an aortic abdominal aneurysm is suspected, immediate referral to a vascular surgeon is essential, because an aortic abdominal aneurysm can lead to severe ischemia of the abdominal organs and a rupture will cause hypovolemic shock. ${ }^{16}$ Since many inflammatory and noninflammatory diseases can contribute to the development of aortic aneurysms, appropriate systemic evaluation of the patient must be performed. ${ }^{17,18}$ Differences in OPA between the right and left eye are pathological findings and can indicate stenosing diseases in the extracranial arterial vascular bed on the low OPA side. ${ }^{19}$ Moderate ( $>50 \%$ occlusion) to severe ( $>75 \%$ occlusion) carotid occlusive disease reduces OPA significantly ${ }^{20}$ and may lead to an asymmetric OPA measurement. Because carotid occlusive disease is an important risk factor for stroke, measuring OPA is reported to be an excellent and noninvasive test for internal carotid stenosis. ${ }^{19-21}$ In addition to confirming carotid occlusive disease, it has been demonstrated that an OPA difference between the two eyes can diagnose innominate artery steal syndrome $\mathrm{e}^{22}$ and cavernous sinus dural arteriovenous fistula. ${ }^{23}$ If the OPA difference between the two sides is more than $1.6 \mathrm{mmHg}$, the sensitivity to detect cavernous sinus dural arteriovenous fistula is $100 \%$ and the specificity is $93 \% .^{24}$

\section{Conclusion}

As demonstrated by our case reports and a literature review, OPA is a noninvasive, cost-effective, and simple screening tool to detect potentially severe cardiovascular disease in glaucoma patients, who are often asymptomatic. Analyzing OPA levels and rhythm as well as side differences between the eyes can reveal a potentially severe cardiovascular disorder. An immediate referral to the appropriate specialty for further diagnostic and therapeutic procedures may significantly reduce an individual patient's morbidity and mortality risk. In view of the fact that the relationship between a conspicuous OPA and potentially serious cardiovascular disease has mostly been documented only in reports of individual cases or in small case series thus far, further prospective trials involving larger numbers of patients are needed to confirm this potential advantage of OPA measurement.

\section{Disclosure}

The authors report no conflicts of interest in this work.

\section{References}

1. Quickley HA, Vitale S. Models of open-angle glaucoma prevalence and incidence in the United States. Invest Ophthalmol Vis Sci. 1997;38:83-91.

2. Flammer J, Orgül S, Costa VP, et al. The impact of ocular blood flow in glaucoma. Prog Retin Eye Res. 2002;21:359-393.

3. Kniestedt C, Kanngiesser HE. Dynamische Konturtonometrie [Dynamic contour tonometry.] Ophthalmologe. 2006;103:713-723. German.

4. Romppainen T, Kniestedt C, Bachmann LM, Stürmer J. Okuläre Pulsamplitude als biometrischer Messwert in der Glaukomdiagnostik [Ocular pulse amplitude: a new biometrical parameter for the diagnose of glaucoma?]. Ophthalmologe. 2007;104:230-235. German.

5. Yanagi M, Kawasaki R, Wang JJ, Wong TY, Crowston J, Kiuchi Y. Vascular risk factors in glaucoma: a review. Clin Exp Ophthalmol. 2011;39:252-258.

6. Trew DR, James B, Thomas SHL, Sutton R, Smith SE. Factors influencing the ocular pulse - the heart rate. Graefes Arch Clin Exp Ophthalmol. 1991;229:553-556.

7. Kanngiesser HE, Kniestedt C, Robert YC. Dynamic contour tonometry: presentation of a new tonometer. J Glaucoma. 2005;14:344-350.

8. Perkins ES. The ocular pulse. Curr Eye Res. 1981;1:19-23.

9. Kaufmann C, Bachmann LM, Robert YC, Thiel MA. Ocular pulse amplitude in healthy subjects as measured by dynamic contour tonometry. Arch Ophthalmol. 2006;124:1104-1108.

10. Knecht PB, Bosch MM, Michels S, et al. The ocular pulse amplitude at different intraocular pressure: a prospective study. Acta Ophthalmol. 2011;89:e466-e471.

11. Pourjavan S, Boelle PY, Detry-Morel M, De Potter P. Physiological diurnal variability and characteristics of the ocular pulse amplitude (OPA) with the dynamic contour tonometer (DCT-Pascal). Int Ophthalmol. 2007;27:357-360.

12. Grieshaber MC, Katamy R, Gugleta K, Kochkorov A, Flammer J, Orgül S. Relationship between ocular pulse amplitude and systemic blood pressure measurements. Acta Ophthalmol. 2009;87:329-334. 
13. Wolf PA, Abbott RD, Kannel WB. Atrial fibrillation as an independent risk factor for stroke: the Framingham study. Stroke. 1991; 22:983-988.

14. Cairns JA, Connolly S, McMurtry S, Stephenson M, Talajic M. CCS atrial fibrillation guidelines committee: Canadian cardiovascular society atrial fibrillation guidelines 2010: prevention of stroke and systemic thrombembolism in atrial fibrillation and flutter. Can J Cardiol. 2011;27:74-90.

15. Rutzen-Lopez H, Khanna V, Reynolds R. Atrial fibrillation: epidemiology, prognosis and therapy. Minerva Med. 2011;102:187-208.

16. Lewiss RE, Egan DJ, Shreves A. Vascular abdominal emergencies. Emerg Med Clin North Am. 2011;29:253-272.

17. Metcalfe D, Holt PJE, Thompson MM. The management of abdominal aortic aneurysms. BMJ. 2011;342:d1384.

18. Miller DV, Maleszewski JJ. The pathology of large-vessel vasculitides. Clin Exp Rheumatol. 2011;29(1 Suppl 64):92-98.

19. Knecht PB, Menghini M, Bachmann LM, Baumgartner RW, Landau K. The ocular pulse amplitude as a noninvasive parameter for carotid artery stenosis screening: a test accuracy study. Ophthalmology. 2012; 119:1244-1249.

20. Langham ME, Prezioso TJ. Non-invasive diagnosis of mild to severe stenosis of the internal carotid artery. Stroke. 1984;15:614-621.
21. Perkins ES. The ocular pulse and intraocular pressure as a screening test for carotid artery stenosis. Br J Ophthalmol. 1985;69:676-680.

22. Kaufmann C, Fierz A, Kollias SS, et al. Ocular pulse amplitude in a case of innominate steal syndrome. Am J Ophthalmol. 2002;133: $155-156$.

23. Takai Y, Tanito M, Miyazaki T, Sugimoto K, Akiyama Y, Ohiro A. Ocular pulse amplitude measured by PASCAL dynamic contour tonometry in patients with a cavernous sinus dural arteriovenous fistula. Acta Ophthalmol. 2012;90:e333-e335.

24. Golnik KC, Miller NR. Diagnosis of cavernous sinus arteriovenous fistula by measurement of ocular pulse amplitude. Ophthalmology. 1992;99:1146-1152.

25. Detry-Morel M, Jamart J, Detry MB, Ledoux A, Pourjavan S. [Clinical evaluation of the Pascal dynamic contour tonometer]. J Fr Ophthalmol. 2007;30:260-270. French.

26. Choi J, Lee J, Park SB, Lee KS, Sung KR, Kook MS. Factors affecting ocular pulse amplitude in eyes with open angle glaucoma and glaucoma suspect eyes. Acta Ophthalmol. 2012;90:552-558.

27. McKee HD, Saldana M, Ahad MA. Increased ocular pulse amplitude revealing aortic regurgitation. Am J Ophthalmol. 2004;138:503.
Clinical Ophthalmology

\section{Publish your work in this journal}

Clinical Ophthalmology is an international, peer-reviewed journal covering all subspecialties within ophthalmology. Key topics include: Optometry; Visual science; Pharmacology and drug therapy in eye diseases; Basic Sciences; Primary and Secondary eye care; Patien Safety and Quality of Care Improvements. This journal is indexed on

Submit your manuscript here: http://www.dovepress.com/clinical-ophthalmology-journal

\section{Dovepress}

PubMed Central and CAS, and is the official journal of The Society of Clinical Ophthalmology (SCO). The manuscript management system is completely online and includes a very quick and fair peer-review system, which is all easy to use. Visit http://www.dovepress.com/ testimonials.php to read real quotes from published authors. 